\title{
Are Overweight and Obese Youth at Increased Risk for Physical Activity Injuries?
}

\author{
Joel Warsh ${ }^{\mathrm{a}}$ William Pickett ${ }^{\mathrm{a}, \mathrm{b}}$ Ian Janssen ${ }^{\mathrm{a}, \mathrm{c}}$

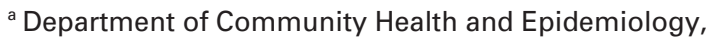 \\ ${ }^{\mathrm{b}}$ Department of Emergency Medicine,

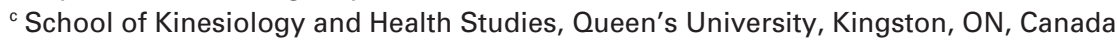

\section{Keywords}

Obesity · Injury · Physical activity · Youth · Epidemiology

\section{Summary}

Objective: To determine whether relationships between physical activity and physical activity injuries are modified by BMI status in youth. Method: Data were obtained from the 2006 Canadian Health Behaviour in SchoolAged Children survey; a representative study of 7,714 grade 6-10 youth. A sub-sample of 1,814 were re-administered the survey in 2007. Analyses considered relationships among the major variables in theory-driven crosssectional and longitudinal analyses. Result: Among normal weight youth, cross-sectional analyses indicated that those who reported high levels of physical activity outside of school experienced 2.28 (95\% confidence interval 1.95-2.68) the relative odds for physical activity injury in comparison to those with low levels of physical activity outside of school. Analogous odds ratios for overweight and obese youth were 1.89 (1.31-2.72) and 3.72 (1.89-7.33), respectively. BMI status was not an effect modifier of the relationship between physical activity and physical activity injury. Similar observations were made in the confirmatory longitudinal analyses. Conclusion: Concerns surrounding the design of physical activity programmes include side-effects such as injury risk. This study provides some re-assurance that physical activity participation relates to injury in a consistent manner across BMI groups.

\section{Introduction}

Obesity is a leading public health problem among young people. The prevalence of overweight and obese youth has already reached epidemic proportions in most developed countries [1], and the rapidly increasingly problem of childhood obesity in developing countries [2] suggests that the global burden of obesity will continue to escalate in the coming years. To reduce the prevalence of overweight and obese youth, efforts are underway to increase physical activity participation [3]. Recently published evidence-based physical activity guidelines for school-aged children and youth suggest a minimum of 60 min of moderate-to-vigorous intensity physical activity on a daily basis, with a focus on aerobic activities [4]. The evidence that informed these recommendations focused on the positive aspects of physical activity. However, physical activity is also a leading determinant of medically treated injuries in youth [5]. Studies that examine the negative effects of physical activity are warranted in order to inform physical activity recommendations that are optimal for both health and safety.

BMI status may play a modifying role in the relationship between physical activity and physical activity injuries such that overweight and obese youth may be subject to an increased injury risk for a given level of physical activity than normal weight youth. Because overweight and obese children are vulnerable populations who are encouraged to engage in high levels of physical activity to manage their excess BMI, it is vital to identify whether physical activity participation places them at increased risk for injury.

The objective of this study was to examine the potential modifying effects of BMI status on the relationship between physical activity and physical activity injuries. This was done using a large, nationally representative sample of youth aged 11-15 years. The study provides novel data that can be helpful for physical activity programme planning for obesity and injury prevention.

\begin{tabular}{ll}
\hline KARGER & $\oplus$ c 2010 S. Karger GmbH, Freiburg \\
Fax +497614520714 & Accessible online at: \\
Information@Karger.de & www.karger.com/ofa \\
www.karger.com &
\end{tabular}




\section{Material and Methods}

\section{Sample}

The study involved a cross-sectional analysis of health data collected from Canadian children, with longitudinal confirmation of key relationships. The principle data source was the 2006 Canadian Health Behaviour in School-Aged Children (HBSC) survey [3]. This survey was conducted in collaboration with the World Health Organization and follows an international scientific protocol [6]. The HBSC employed a cluster design, with randomly selected classrooms reflecting provincial distributions of schools by size, location, language, and religion [6]. Youth attending special schools (private, special-need, home), incarcerated youth, and street youth were excluded; however, these youth represented less than $10 \%$ of the defined population in Canada [7]. Self-reported information on demographic and psychosocial factors, health behaviours, and health outcomes was collected from participants. Approximately $75 \%$ of students that were approached participated [6].

The 2006 cross-sectional sample involved 9,672 youth in grades 6-10 (representing ages 11-15 years) from 188 schools. Most of the schools were public $(82.4 \%)$ and situated in urban areas $(61.8 \%)$. Students were excluded from the present analysis due to incomplete information on BMI $(\mathrm{n}=1,735)$, physical activity $(\mathrm{n}=128)$, and injuries $(\mathrm{n}=68)$. Records from $7,741(80 \%)$ of the students were analyzed. Those who were not included tended to be younger and a greater percentage were female (data not shown).

In addition to the national sample, 2,039 grade 9 and 10 students from 15 high schools in the province of Ontario were administered the HBSC on two occasions, in the spring of 2006 and 1 year later in 2007. Of these, $1,814(89 \%)$ provided complete data for the BMI and physical activity variables at baseline (2006) and the injury items at follow-up (2007) and were available for the longitudinal analyses. The longitudinal analyses were primarily conducted to confirm the results of the cross-sectional analyses, which were conducted in a much larger and more representative sample.

\section{Exposure - Physical Activity}

Three HBSC items measured i) the number of hours of moderate-tovigorous intensity physical activity performed in school during class time, ii) the number of hours of moderate-to-vigorous physical activity performed in school during free time, and iii) the number of hours of moderate-to-vigorous physical activity performed outside of school. For the within school physical activity questions, there were 9 response categories that ranged from 'none' to '7 h or more per week' [8]. The two measures (in class and in free time) were summed to create an overall measure of in-school physical activity. For physical activity outside of school, there were 7 possible response categories that ranged from 'none' to ' $7 \mathrm{~h}$ or more per week' [8]. Both the in-school and outside of school physical activity scores were grouped into low ( $<3 \mathrm{~h} /$ week), moderate (3-6 h/week), and high ( $\geq 7 \mathrm{~h} /$ week) categories [8]. These categories corresponded with total daily moderate-to-vigorous physical activity levels of $<30 \mathrm{~min}, 30-60$ $\min$, and $\geq 60 \mathrm{~min}$ [8]. Cut-points were chosen based on prior research [9, 10]. The self-reported physical activity questions used here provide reasonably valid estimates when compared with objective measures from accelerometer data, with kappa values of 0.6 [11, 12].

\section{Outcome - Physical Activity Injuries}

An initial question that stated 'During the past 12 months, how many times were you injured and had to be treated by a doctor or nurse?' was used to identify reported injury events. Medically treated injury occurrences that result in a loss of normal activity has been recommended as a valid [13] and reliable proxy for defining injury in survey data, with kappa scores of 0.89-0.92 [14]. A series of follow-up questions requested information on the activity leading to the injury and the physical location where the injury occurred. Physical activity injuries were defined as those occurring due to 'biking/cycling', 'playing or training for sports/recrea- tional activity', 'skating', or 'walking/running'. Each physical activity injury reported was also classified as occurring either on or off school grounds [8].

\section{Potential Effect Modifier - BMI Status}

The BMI, calculated as self-reported values for weight in $\mathrm{kg}$ divided by height in $\mathrm{m}^{2}\left(\mathrm{~kg} / \mathrm{m}^{2}\right)$, is the most commonly used index of BMI status among youth [15]. The International Obesity Task Force age-and genderspecific BMI standards for youth were used to classify participants as being normal weight, overweight, or obese [16]. Growth curves have been created for use in calculating BMI status in youth where at age 18, the curves pass through the adult cut-points of 25 (overweight) and 30 (obese) $\mathrm{kg} / \mathrm{m}^{2}$.

Self-reported BMI is a reliable method of measurement despite slight underestimation, particularly among females [17, 18]. High correlations between self-reported and measured height, weight and BMI have been reported. Measured and self-reported values also relate to health outcomes in a similar manner $[17,18]$.

\section{Confounders}

Variables considered a priori as potential confounders were gender, grade, socioeconomic status, and perceived health. Females are less physically active than males, and male youth become injured more than girls [19]. Furthermore, older youth are less physically active and more prone to injury [19]. Socioeconomic status was measured via the Family Affluence Scale (FAS). Responses to questions regarding vehicle and computer ownership, bedroom sharing, and holiday travel contribute to this scale [20]. The FAS is reliable in that student reports are in agreement with parental reports. It is also sensitive in distinguishing between varying levels of affluence measured using alternative methods [20]. Perceived health was considered to be important as youth are known to be less physically active if they are not healthy [21, 22] and individuals with health complications are more likely to become injured [23, 24]. Selfreported measures of health have been proven to be reliable indicators of general health status in large population health surveys [25].

\section{Statistical Analysis}

Descriptive analyses were used to profile characteristics of the 2006 national cross-sectional sample. Next, a series of logistic regression analyses were conducted. Model development was based upon a priori identification of potential confounders from existing literature. A backwards stepwise selection procedure confirmed a parsimonious set of confounders for potential analyses in multiple logistic regression models [19]. A product term of physical activity $\times$ BMI status (normal weight, overweight, obese) was included to evaluate effect modification. The logistic regression modelling approach used in the cross-sectional sample was repeated in the longitudinal sample. All statistical analyses were performed using SAS version 9.1 (SAS Institute, Cary NC, USA). Error estimates and 95\% confidence intervals $(95 \% \mathrm{CI})$ were adjusted in the models using the SURVEYLOGISTIC procedures to account for the clustering by school class. The SURVEYLOGISTIC procedure calculates variance estimates within each cluster and then pools the estimates together.

\section{Results}

\section{Cross-Sectional Analyses}

The nationally representative cross-sectional sample is described in table 1. Larger percentages of youth experienced physical activity injuries outside of school $(23.2 \%)$ as compared to in school $(5.9 \%)$. The majority of participants reported being in the low physical activity group for all three physical activity measures. Of the 2,250 (29.1\%) who reported 
Table 1. Descriptive analysis of the student sample $(n=7,741)$

\begin{tabular}{|c|c|c|}
\hline Variable & $\mathrm{N}$ & $\%$ \\
\hline \multicolumn{3}{|l|}{ Gender } \\
\hline Male & 3,730 & 48.2 \\
\hline Female & 4,011 & 51.8 \\
\hline \multicolumn{3}{|l|}{ Grade } \\
\hline $6-8$ & 4,001 & 51.7 \\
\hline $9-10$ & 3,740 & 48.3 \\
\hline \multicolumn{3}{|l|}{ Physical activity injuries } \\
\hline Occurred in school & 458 & 5.9 \\
\hline Occurred outside of school & 1,792 & 23.2 \\
\hline \multicolumn{3}{|c|}{ Physical activity in class time at school } \\
\hline Low (<3 h/week) & 4,678 & 60.4 \\
\hline Moderate (3-6 h/week) & 2,579 & 33.3 \\
\hline High $(\geq 7 \mathrm{~h} /$ week $)$ & 484 & 6.2 \\
\hline \multicolumn{3}{|c|}{ Physical activity in free time at school } \\
\hline Low (<3 h/week) & 4,818 & 62.2 \\
\hline Moderate (3-6 h/week) & 2,252 & 29.1 \\
\hline High $(\geq 7 \mathrm{~h} /$ week $)$ & 671 & 8.7 \\
\hline \multicolumn{3}{|l|}{ Physical activity outside of school } \\
\hline Low (<3 h/week) & 4,699 & 60.7 \\
\hline Moderate (3-6 h/week) & 1,666 & 21.5 \\
\hline High ( $\geq 7$ h/week) & 1,376 & 17.8 \\
\hline \multicolumn{3}{|l|}{ BMI category } \\
\hline Normal weight & 6,111 & 78.9 \\
\hline Overweight & 1,211 & 15.6 \\
\hline Obese & 419 & 5.4 \\
\hline
\end{tabular}

having a medically treated physical activity injury in the past year, 1,723 were treated in a doctor's office or health clinic, 1,128 were treated in an emergency room, 356 required an overnight hospital admission, and 233 were treated by school health services.

Bivariate associations between physical activity injury and each of the potential confounders are presented in table 2 . Outside of school, youth reported a higher relative odds for physical activity injury if they were in grades 9-10, male, had a moderate or high socioeconomic status, and had 'excellent' perceived health.

Table 3 summarizes the relationships between physical activity and physical activity injuries experienced in and out of schools, stratified by BMI status in the cross-sectional sample. All of the analyses in table 3 were adjusted for grade, gender, the FAS, and perceived health. In normal weight youth, those who performed high levels of physical activity in their free time at school had 1.57 (95\% CI 1.11-2.24) times the risk for physical activity injury in comparison with those who reported low levels. Normal weight youth who performed high levels of physical activity outside of school experienced 2.28 (95\% CI 1.95-2.68) times the risk for physical activity injury outside of school in comparison to normal weight youth with low physical activity participation. Likewise, overweight youth who performed high levels of physical activity outside of school experienced 1.89 (95\% CI 1.312.72) times the risk for physical activity injury outside of school in comparison to overweight youth with low physical
Table 2. Bivariate associations between confounding variables and physical activity injury

\begin{tabular}{|c|c|c|c|c|}
\hline \multirow[t]{3}{*}{ Variable } & \multicolumn{4}{|c|}{ Physical activity injury } \\
\hline & \multicolumn{2}{|l|}{ in school } & \multicolumn{2}{|c|}{ outside of school } \\
\hline & $\%$ injured & OR $(95 \% \mathrm{CI})$ & $\%$ injured & OR (95\% CI) \\
\hline \multicolumn{5}{|l|}{ Grade } \\
\hline $6-8$ & 6.0 & 1.00 & 22.3 & 1.00 \\
\hline $9-10$ & 5.8 & $0.97(0.80-1.17)$ & 24.1 & $1.10(0.99-1.23)$ \\
\hline \multicolumn{5}{|l|}{ Gender } \\
\hline Male & 6.0 & 1.00 & 27.5 & 1.00 \\
\hline Female & 5.8 & $0.96(0.80-1.16)$ & 19.1 & $0.62(0.56-0.69)$ \\
\hline \multicolumn{5}{|l|}{ FAS } \\
\hline Low & 6.8 & 1.00 & 15.2 & 1.00 \\
\hline Moderate & 6.0 & $0.87(0.61-1.23)$ & 21.3 & $1.51(1.19-1.91)$ \\
\hline \multirow[t]{2}{*}{ High } & 5.9 & $0.85(0.61-1.19)$ & 25.8 & $1.94(1.54-2.43)$ \\
\hline & & $\mathrm{P}$ trend $=0.44$ & & $\mathrm{P}$ trend $<0.001$ \\
\hline \multicolumn{5}{|c|}{ Perceived health } \\
\hline Excellent & 5.2 & 1.00 & 28.3 & 1.00 \\
\hline Good & 6.2 & $1.19(0.97-1.46)$ & 22.5 & $0.74(0.66-0.83)$ \\
\hline Fair & 6.8 & $1.32(0.98-1.79)$ & 15.5 & $0.46(0.38-0.56)$ \\
\hline \multirow[t]{2}{*}{ Poor } & 2.3 & $0.42(0.13-1.35)$ & 10.7 & $0.30(0.17-0.53)$ \\
\hline & & $\mathrm{P}$ trend $=0.25$ & & $\mathrm{P}$ trend $<0.001$ \\
\hline
\end{tabular}

OR $(95 \% \mathrm{CI})=$ odds ratio $(95 \%$ confidence interval $)$. 
Table 3. Multivariate associations between physical activity and physical activity injury within BMI categories in the cross-sectional sample
Table 4. Multivariate associations between physical activity and physical activity injury within BMI categories in the longitudinal sample

\begin{tabular}{|c|c|c|c|c|}
\hline & $\begin{array}{l}\text { Normal weight } \\
\text { OR }(95 \% \mathrm{CI}) *\end{array}$ & $\begin{array}{l}\text { Overweight } \\
\text { OR }(95 \% \mathrm{CI})^{*}\end{array}$ & $\begin{array}{l}\text { Obese } \\
\text { OR }(95 \% \mathrm{CI}) *\end{array}$ & $\begin{array}{l}\text { Physical activity level } \times \\
\text { BMI category interaction }\end{array}$ \\
\hline \multicolumn{5}{|c|}{ Physical activity level in class time at school } \\
\hline Low $(<3 \mathrm{~h} /$ week $)$ & 1.00 & 1.00 & 1.00 & \multirow{4}{*}{$\mathrm{P}=0.97$} \\
\hline Moderate (3-6 h/week) & $1.12(0.89-1.42)$ & $0.98(0.56-1.72)$ & $1.46(0.70-3.07)$ & \\
\hline \multirow[t]{2}{*}{ High ( $\geq 7$ h/week) } & $1.35(0.88-2.06)$ & $0.41(0.10-1.77)$ & $4.39(0.93-20.79)$ & \\
\hline & $\mathrm{P}$ trend $=0.13$ & $\mathrm{P}$ trend $=0.36$ & $\mathrm{P}$ trend $=0.09$ & \\
\hline \multicolumn{5}{|c|}{ Physical activity level in free time at school } \\
\hline Low (<3 h/week) & 1.00 & 1.00 & 1.00 & \multirow{4}{*}{$\mathrm{P}=0.88$} \\
\hline Moderate (3-6 h/week) & $1.25(0.98-1.59)$ & $0.79(0.44-1.43)$ & $1.34(0.61-2.99)$ & \\
\hline \multirow[t]{2}{*}{$\operatorname{High}(\geq 7 \mathrm{~h} /$ week $)$} & $1.57(1.11-2.24)$ & $1.41(0.60-3.33)$ & $1.55(0.44-5.05)$ & \\
\hline & $\mathrm{P}$ trend $=0.005$ & $\mathrm{P}$ trend $=0.88$ & $\mathrm{P}$ trend $=0.35$ & \\
\hline \multicolumn{5}{|c|}{ Physical activity level outside of school } \\
\hline Low $(<3 \mathrm{~h} /$ week $)$ & 1.00 & 1.00 & 1.00 & \multirow{4}{*}{$P=0.72$} \\
\hline Moderate (3-6 h/week) & $1.79(1.54-2.09)$ & $1.73(1.25-2.46)$ & $1.57(0.73-3.38)$ & \\
\hline \multirow[t]{2}{*}{ High ( $\geq 7$ h/week) } & $2.28(1.95-2.68)$ & $1.89(1.31-2.72)$ & $3.72(1.89-7.33)$ & \\
\hline & $\mathrm{P}$ trend $<0.001$ & $\mathrm{P}$ trend $<0.001$ & $\mathrm{P}$ trend $<0.001$ & \\
\hline
\end{tabular}

OR $(95 \% \mathrm{CI})=$ Odds ratio $(95 \%$ confidence interval $)$.

*Multivariate OR were adjusted for grade, gender, FAS, and perceived health.

\begin{tabular}{|c|c|c|c|c|}
\hline & $\begin{array}{l}\text { Normal weight } \\
\text { OR }(95 \% \mathrm{CI}) *\end{array}$ & $\begin{array}{l}\text { Overweight } \\
\text { OR }(95 \% \mathrm{CI})^{*}\end{array}$ & $\begin{array}{l}\text { Obese } \\
\text { OR }(95 \% \mathrm{CI})^{*}\end{array}$ & $\begin{array}{l}\text { Physical activity level } \times \\
\text { BMI category interaction }\end{array}$ \\
\hline \multicolumn{5}{|c|}{ Physical activity level in class time at school } \\
\hline Low $(<3 \mathrm{~h} /$ week $)$ & 1.00 & 1.00 & 1.00 & \multirow{4}{*}{$\mathrm{P}=0.70$} \\
\hline Moderate (3-6 h/week) & $1.21(0.73-2.02)$ & $0.93(0.30-2.89)$ & $0.28(0.01-6.85)$ & \\
\hline \multirow[t]{2}{*}{ High ( $\geq 7$ h/week) } & $0.74(0.25-2.22)$ & $1.91(0.36-10.30)$ & -- & \\
\hline & $\mathrm{P}$ trend $=0.96$ & $\mathrm{P}$ trend $=0.70$ & $\mathrm{P}$ trend $=0.27$ & \\
\hline \multicolumn{5}{|c|}{ Physical activity level in free time at school } \\
\hline Low $(<3 \mathrm{~h} /$ week $)$ & 1.00 & 1.00 & 1.00 & \multirow{4}{*}{$P=0.70$} \\
\hline Moderate (3-6 h/week) & $1.45(0.82-2.54)$ & $1.39(0.47-4.08)$ & $2.27(0.39-13.26)$ & \\
\hline High $(\geq 7 \mathrm{~h} /$ week $)$ & $2.61(1.27-5.35)$ & $1.36(0.24-7.66)$ & $2.80(0.19-42.34)$ & \\
\hline & $\mathrm{P}$ trend $=0.01$ & $\mathrm{P}$ trend $=0.57$ & $\mathrm{P}$ trend $=0.36$ & \\
\hline \multicolumn{5}{|c|}{ Physical activity level outside of school } \\
\hline Low $(<3 \mathrm{~h} /$ week $)$ & 1.00 & 1.00 & 1.00 & \multirow{4}{*}{$\mathrm{P}=0.07$} \\
\hline Moderate (3-6 h/week) & $2.08(1.52-2.84)$ & $2.56(1.22-5.34)$ & $1.20(0.27-5.36)$ & \\
\hline \multirow[t]{2}{*}{ High $(\geq 7 \mathrm{~h} /$ week $)$} & $2.86(2.05-3.97)$ & $1.78(0.78-4.11)$ & $0.94(0.14-6.48)$ & \\
\hline & $\mathrm{P}$ trend $<0.001$ & $\mathrm{P}$ trend $<0.06$ & $\mathrm{P}$ trend $<0.98$ & \\
\hline
\end{tabular}

OR $(95 \% \mathrm{CI})=$ Odds ratio $(95 \%$ confidence interval $) ;--=$ no observations.

*Multivariate OR were adjusted for grade, gender, FAS, and perceived health. activity participation. The corresponding odds ratio for the obese youth was 3.72 (95\% CI 1.89-7.33). The 95\% CI for the class time and free time at school physical activity injury risk estimates in the obese group are quite large, due to the smaller sample size of the obese group and the limited number of injuries occurring in the school environment, and the risk estimates within this BMI category should therefore be interpreted with caution.

There were no significant interaction effects, indicating that the relationships between physical activity level and injury did not vary by BMI status. This was true for the class time at school $(\mathrm{P}=0.97)$, free time at school $(\mathrm{P}=0.88)$, and outside of school $(\mathrm{P}=0.72)$ physical activity measures and injury outcomes.

\section{Longitudinal Analyses}

Table 4 presents the results of the confirmatory longitudinal regression analyses conducted in the subsample of 1,814 grade 9 and 10 youth from the province of Ontario. Due to the small sample size $(\mathrm{n}=88)$ and large $95 \% \mathrm{CI}$, the results for the obese group should be interpreted with caution. The pattern of relationships in the longitudinal analyses were similar to 
those found in the cross-sectional analyses. Within the normal weight and overweight BMI categories, youth with moderate and high levels of physical activity outside of school were at greater risk for physical activity injuries in comparison to youth who were not physically active. BMI status did not modify the relationship between physical activity and physical activity injuries, both the within and outside of school settings.

\section{Discussion}

Findings from this study demonstrate that youth who engage in high levels of physical activity outside of school experience higher risks for physical activity injuries. However, relationships between physical activity level and injury did not vary across normal weight, overweight, and obese youth. This study provides re-assurance that physical activity participation relates to injury in a consistent manner across BMI groups.

Six published studies indicate that there are significant differences in overall injury risk [26, 27], wrist fractures [28], ankle injuries [29], and musculoskeletal pain of the joints [30] across BMI groups in young people. In particular, overweight and obese children and youth tend to have higher injury risks than children and youth with a healthy BMI. These studies did not consider the moderating impact of BMI on the mechanism leading to the injury, such as physical activity participation, which was the main purpose of our study. Thus, our study makes a unique contribution to the literature by demonstrating the BMI status does not modify the relationships between physical activity participation (the leading cause of injuries) and injury risk in youth.

We did not find evidence of a modifying effect of BMI status on injury risk. This may be attributable to the fact that specific types and anatomical sites of injury were not available for examination. For example, it is possible that these effects could be observed for fractures and soft tissue injuries to the lower limbs, each of which could be biomechanically related to the forces associated with larger body weights. Our analyses were only able to study combined groups of fractures and other injuries, due to the lack of information on anatomical site. This would have biased any observed effects towards the null, and masked the existance of such findings.

The minimal differences in the size of effect estimates between physical activity and injury observed between BMI groups provides encouraging news for programme planners and physical activity educators. Physical activity is a recommended method of weight and BMI control in paediatric obesity treatment programmes [31,32] and has demonstrated benefits in addition to weight maintenance/loss in youth including improved psychosocial health, bone growth, blood pressure, asthma symptoms, and muscular strength and endurance $[9,33,34]$. Being overweight did not exacerbate the risks for physical activity injury in our study. By extension and taken in context of the literature, our findings suggest that physical activity should continue to be used as an integral part of weight reduction programmes within overweight and obese youth as it did not carry an added risk for injury, a key negative health outcome of physical activity.

Strengths of this study include the fact that it was based on a large sample of Canadian youth, the validated survey procedures, the multilevel modelling used for analysis, and the confirmation of the cross-sectional findings in the longitudinal component of the analyses. Limitations of this study also warrant comment. These include bias introduced by the use of self-reported information. Physical activity levels are likely to be overestimated by participating students, and questionnaire measures of physical activity are poorly related to objective measures [6]. This misclassification would likely be independent of the characteristics of physical activity injury and have biased effect estimates towards the null. Finally, because of the limited sample size of the obese group, particularly for the longitudinal analyses, we were likely underpowered to detect statistically significant relationships in this BMI category.

In summary, current public health and clinical guidelines encourage overweight and obese children to engage in high levels of physical activity to manage their excess BMI [4]. The evidence that informed these guidelines focused on the positive aspects of physical activity. The negative effects of physical activity, such as injury risk, also need to be considered to ensure that physical activity guidelines are optimal for both health and safety. The results of this study suggest that relationships between physical activity level and injury did not vary across normal weight, overweight, and obese youth. These are encouraging findings that suggest that overweight and obese youth who engage in high levels of physical activity are not particularly vulnerable to the burden of injury.

\section{Acknowledgements}

This study was supported financially by the Canadian Institutes of Health Research (Grants MOP 394-792 and MOP-CHI-128223) and the Public Health Agency of Canada (Contract: HT089-05205/001/SS) which funds the Canadian version of the Health Behaviour in School-Aged Children survey; a World Health Organization / European Region collaborative study. International Coordinator of the 2005/2006 study: Candace Currie, University of Edinburgh; Data Bank Manager: Oddrun Samdal, University of Bergen. We further would like to thank all individuals who collected national and provincial data. This publication reports data solely from Canada (Principal Investigator: William Boyce and Ontario Principal Investigator William Pickett). Ian Janssen was funded by a New Investigator Award from Canadian Institutes of Health Research and an Early Researcher Award from the Ontario Ministry of Research and Innovation. Joel Warsh was funded by the Ontario Graduate Scholarship and a Banting and Best Master's award from the Canadian Institutes of Health Research.

\section{Disclosure}

The authors declared no conflict of interest. 


\section{References}

1 Janssen I, Katzmarzyk P, Boyce W, Vereecken C, Mulvihill C, Roberts C, Currie C, Pickett W: Comparison of overweight and obesity prevalence in school-aged youth from 34 countries and their relationships with physical activity and dietary patterns. Obes Rev 2005;6:123-132.

2 Popkin BM, Gordon-Larsen P: The nutrition transition: worldwide obesity dynamics and their determinants. Int J Obes 2004;28(suppl 3):S2-S9.

3 Sothern MS: Obesity prevention in children: physical activity and nutrition. Nutrition. 2004;20:704 708.

4 Physical Activity Guidelines Advisory Committee: Physical Activity Guidelines Advisory Committee Report, 2008. Washington, DC, U.S. Department of Health and Human Services, 2008.

5 Bazelmans C, Godin I, Leveque A: Is obesity associated with injuries among young people? Eur J Epidemiol 2004;19:1037-1042.

6 Currie C, Samdal O, Boyce W, Smith B (eds): World Health Organization. Health Behaviour in School-Aged Children: a World Health Organization Cross-National Study. Research Protocol for the 2001/02 Survey. Edinburgh, University of Edinburgh, 2001.

7 Janssen I, Katzmarzyk P, Boyce W, King M, Pickett W: Overweight and obesity in Canadian adolescents and their associations with dietary habits and physical activity patterns. J Adolesc Health 2004:35:360-367.

8 Janssen I, Dostaler S, Boyce W, Pickett W: Influence of multiple risk behaviors on physical activity-related injuries in adolescents. Pediatrics 2007;119:672-680.

$\checkmark$ Strong W, Malina B, Blimkie C, Daniels SR, Dishman R, Gutin B, Hergenroeder A, Must A, Nixon P, Pivarnik J, Rowland T, Trost S, Trudeau F: Evidence based physical activity for school-age youth. J Pediatr 2005;146:732-737.

10 Fulton J, Garg M, Galuska D, Rattay K, Caspersen C: Public health and clinical recommendations for physical activity and physical fitness: special focus on overweight youth. Sports Med 2004;34:581-599.
1 Booth M, Okely A, Chey T, Bauman A: The reliability and validity of the physical activity questions in the WHO Health Behaviour in School Children (HBSC) survey: a population study. Br J Sports Med 2001;35:263-267.

12 Prochaska J, Sallis J, Long B: A physical activity screening measure for use with adolescents in primary care. Arch Pediatr Adolesc Med 2001;155: 554-559.

13 Christoffel K, Scheidt P, Agran J, Kraus E, McLoughlin J: Standard definitions for childhood injury research: excerpts of a conference report. Pediatrics 1992;89:1027-1034.

14 Durbin D, Winston F, Applegate S, Moll E, Holmes J: Development and validation of the injury severity assessment survey/parent report: a new injury severity assessment survey. Arch Pediatr Adolesc Med 1999;153:404-408.

15 Boyce W (ed): Healthy Setting for Young People in Canada. Ottawa, Public Health Agency of Canada. 2008 ISBN 978-0-662-46967-4.

16 Cole T, Bellizzi M, Flegal K, Dietz W: Establishing a standard definition for child overweight and obesity worldwide: international survey. BMJ 2000; 320:1240-1243.

17 Strauss R: Childhood obesity and self-esteem. Pediatrics 2000;105:15.

18 Brener N, McManus T, Galuska D, Lowry R, Wechsler W: Reliability and validity of self-reported height and weight among high school students. J Adolesc Health 2003;32:281-287.

19 Kohen A, Soubhi H, Raina P: Maternal reports of child injuries in Canada: trends and patterns by age and gender. Inj Prev 2000;6:223-228.

20 Currie C, Molcho M, Boyce W, Holstein B, Torsheim T, Richter M: Researching health inequalities in adolescents: the development of the Health Behaviour in School-Aged Children (HBSC) family affluence scale. Soc Sci Med 2008;66:1429-1436.

21 Riddoch C, Boreham C: The health-related physical activity of children. Sports Med 1995;19:86-102.

22 Sallis J, Prochaska J, Taylor T: A review of correlates of physical activity of children and adolescents. Med Sci Sports Exerc 2000;32:963-975.
23 Scheidt P, Harel Y, Trumble A, Jones D, Overpeck M, Bijur P: The epidemiology of nonfatal injuries among US children and youth. Am J Public Health 1995;85:932-938.

24 Hambidge S, Gonzales R, Steiner J: Epidemiology of pediatric injury-related primary care office visits in the USA. Pediatrics 2002;109:559-565.

25 Idler E, Benyamini Y. Self-rated health and mortality: a review of twenty-seven community studies. J Health Soc Behav 1997;38:21-37.

26 Xiang H, Smith G, Wilkins J, Chen G, Hostetler S, Stallones L: Obesity and risk of nonfatal unintentional injuries. Am J Prev Med 2005;29:41-45.

27 Nearkassem N, Aptel E, d'Houtaud A, Choquet M: School injury and gender differentials: a prospective cohort study. Eur J Epidemiol 2007;22: 327-334.

28 Goulding A, Jones I, Taylor R, Manning P, Williams S: More broken bones: a 4-year double cohort study of young girls with and without distal forearm fractures. J Bone Miner Rec 2000;15:20112018.

29 Zonfrillo M, Seiden J, House E, Shapiro E, Dubrow R, Baker M, Spiro D: The association of overweight and ankle injuries in children. Ambul Pediatr 2008;8:66-69.

30 Stovitz S, Pardee P, Vazquez G, Duval S, Schwimmer J: Musculoskeletal pain in obese children and adolescents. Acta Paediatr 2008;97:489-493.

31 Hills A: Obesity management via diet and exercise intervention. Child Care Health 1988;14:409-416.

32 Gortmaker S, Peterson K, Wiecha J, Sobol A, Dixit S, Fox M, Laird N: Reducing obesity via a school-based interdisciplinary intervention among youth: Planet Health. Arch Pediatr Adolesc Med 1999;153:409-418.

33 Hallal P, Victora C, Azevedo M, Wells J: Adolescent physical activity and health: a systematic review. Sports Med 2006;36:1019-1030.

34 Bailey D, McKay H, Mirwald R, Crocker P, Faulkner R: A six-year longitudinal study of the relationship of physical activity to bone mineral accrual in growing children: the university of Saskatchewan bone mineral accrual study. J Bone Miner Rec 1999;14:1672-1679. 